\title{
Seedling Emergence Comparison of Several Romanian Tomato and Pepper Varieties
}

\author{
Mihaela IORDĂCHESCU, Anca Amalia UDRIȘTE*, Ovidiu JERCA, Liliana BĂDULESCU
}

\author{
Research Center for Studies of Food Quality and Agricultural Products, University of Agronomic Sciences and \\ Veterinary Medicine, Bucharest, Romania \\ *Corresponding author: Anca Amalia UDRIȘTE e-mail: amalia.udriste@qlab.usamv.ro
}

RESEARCH ARTICLE

\begin{abstract}
Nowadays people are turning to sustainable/ecological agriculture. Romanian local varieties with valuable traits can be used to develop novel organic varieties. Nine Romanian tomato (Solanum lycopersicum L.) and seven pepper (Capsicum annuum L.) varieties were compared during seedling emergence in growth chamber and greenhouse conditions. The aim of this study was to observe the variation of several emergence indicators among the varieties of the same species under the same growing conditions, differences that can be correlated with genotype variation in further genotyping research, with the final goal of using these results as a basis for genotype-assisted breeding programs. The present survey demonstrated significant differences in the emergence indicators among the varieties studied, both in the growth chamber and in the greenhouse growing conditions. Ștefănești 24 tomato variety stood out with the longest mean emergence time, mean emergence rate, synchrony and highest uncertainty of emergence, whereas Vladimir pepper variety had the lowest values for percentage of emergence, homogeneity and uncertainty of emergence.
\end{abstract}

Keywords: Capsicum; genotypes; emergence time; synchrony; Solanum.

Received: 01 September 2020 Accepted: 23 January 2021

Published: 14 May 2021

DOI:

15835/buasvmcn-hort:2020.0031

(2) $\odot \Theta \Theta$ Authors. The papers under the Creative Commons Attribution-NonCommercialNoDerivatives 4.0 International License

\section{INTRODUCTION}

Seed germination is an important plant physiological process that incorporates seed imbibition, activation, intra-seminal growth and embryo protrusion (Delian et al., 2010). Following seed germination, the seedlings have to penetrate the soil in order to reach light and be able to start photosynthesis (Briggs, 2016). Emergence is defined as the moment in time when the seedlings stop to relay on the seed parental reserves and start autotrophic nutrition by photosynthesis (Forcella et al., 2000). Seedling emergence can be characterized using several indicators: percentage of emergence, mean emergence time, homogeneity, mean emergence rate, uncertainty and synchrony of emergence (Ranal et al., 2009). All these indicators can be correlated with seed quality/seed vigor. The genetic make-up of the seed, together with the environmental conditions present during emergence have been proven to influence the percentage of emergence, timing and uniformity of seedling emergence, and to further influence the crop yield and marketing quality (Khan et al., 2012).

Healthy food is one of the main concerns of today's society (Coe et al., 2019), so people are turning to ecological labeled products for consume (Tobler et al., 2011). Therefore, researchers are looking to develop novel organic varieties with superior traits, based on consumer preferences (Rocha et al., 2013). In Romania, tomato is the most cultivated vegetable species (Zamfir et al., 2017). Organic tomatoes have a high content of bioactive compounds, such as carotenoid and lycopen (Bujor et al., 2019; Dobrin et al., 2019). The breeders are constantly reporting 
the creation of new pepper and tomato varieties that are in accordance with consumers' demands (Vînătoru and Neicu, 2010; Vînătoru et al., 2016; Barcanu-Tudor et al., 2018). A study for checking the suitability of local tomato landraces for organic crop production in plastic tunnels identified three landraces that are suitable (Maxim et al., 2013).

In present varieties, many times desirable traits come at the cost of less desirable traits such as low percentage of emergence (Foolad and Panthee, 2012). Khan et al. (2012) have identified 62 major Quantitative Trait Loci (QTLs) on 21 different positions for seed, seedlings and root system architecture traits in tomato. By correlating the differences in emergence indicators with the results of genotyping studies, breeders can select plants with multiple desirable traits in genotype-assisted breeding programs (Santos et al., 2015; Kim et al., 2016).

The aim of the present study was to compare nine tomato varieties and seven pepper varieties during seedling emergence process in the growth chamber and in the greenhouse, based on six indicators of seedling emergence: percentage of emergence, mean emergence time, homogeneity, mean emergence rate, uncertainty and synchrony of emergence.

\section{MATERIALS AND METHODS}

Tomato seeds from 'Argeș 11', 'Argeș 20', 'Ștefănești 24' and 'Ștefănești 22' Romanian varieties were received from I.N.C.D.B.H. Ștefănești-Argeș and tomato seeds from 'Kristinica', 'Florina 44', 'Andrada', 'Buzău 1600' and 'Buzău 47' varieties as well as pepper seeds from 'Decebal', 'Vladimir', 'Galben Superior', 'Splendens', 'Cosmin', 'Roial' and 'Cantemir' Romanian varieties were received from S.C.D.L. Buzău. All experiments and measurements were performed in the laboratories and the greenhouse of Research Center for Studies of Food Quality and Agricultural Products (https://erris.gov.ro/RESEARCH-CENTER-FOR-STUDIES--1).

Seeds were sown on Kekkila brown OPM $0.25 \mathrm{~W}$ substrate in trays with $7 \times 10$ cells. Sowing was done using a wooden stick to make $1.5 \mathrm{~cm}$ holes in the soil, then placing one seed in each hole and covering it with the soil. Seedlings were considered emerged when the seedling's apical hook was visible above the soil, basically when the seedling reached light and could start photosynthesis. Seedling emergence was counted once a day and the process was considered finished when no new seedlings emerged for three days consecutively. Several emergence indicators were monitored during seedling emergence: percentage of emergence (\%), mean emergence time (day), homogeneity (\%), mean emergence rate (day-1), uncertainty (bit) and synchrony of emergence (unitless).

In the Memmert HPP 750 growth chamber (Memmert GmbH + Co. KG, Schwabach, Germany), the experiment was carried out at $80 \%$ air relative humidity, constant temperature of $22^{\circ} \mathrm{C}$, and 14 hours day $/ 10$ hours night conditions. In the greenhouse, the experiment was carried out at natural light conditions, a temperature of $23-27^{\circ} \mathrm{C}$ daytime $/ 17-18^{\circ} \mathrm{C}$ nighttime, and an average of $55 \%$ air relative humidity. For each variety were used three replications, with 23 seeds in each replication. Physiological indicators associated with seedling emergence were calculated following the procedure described by Ranal et al. (2009). Data was statistically analyzed by ANOVA and Duncan's multiple range test (DMRT) using Microsoft Excel 2016 and IBM SPSS Statistics (version 27) software.

\section{RESULTS AND DISCUSSIONS}

\section{Tomato seedling emergence}

Nine Romanian tomato varieties were compared for several physiological indicators of seedling emergence: percentage of emergence, mean emergence time, homogeneity, mean emergence rate, uncertainty of emergence and emergence synchrony.

In the growth chamber (Figure 1), in the case of emergence percentage, over 80\% emergence was observed for the 'Florina 44', 'Andrada' and 'Buzau 47' varieties, whereas the 'Argeș 11' variety displayed the lowest percentage of emergence (22.9\%). The longest mean emergence time was observed for the 'Ștefănești 24 ' variety ( 13 days). All the other varieties emerged between 5 and 7 days. In the case of homogeneity, expressed by the coefficient of variation of the emergence, there were no significant differences among the varieties studied at $\mathrm{P}<0.05$, except for 'Florina 44', which had a value significantly higher than 'Andrada' and 'Argeș 11 ' at $\mathrm{P}<0.05$. Mean emergence rate varied significantly among the tomato varieties. The highest value for the emergence rate was observed for the 'Florina 44' $\left(0.21\right.$ day $\left.^{-1}\right)$, whereas the lowest emergence rate was observed for Ștefănești $24\left(0.07\right.$ day $\left.^{-1}\right)$. In the case of uncertainty of emergence, the highest value was observed for 'Ștefănești 24 ' variety (2.64 bit) and the lowest value for the 'Buzău 47' variety (1.11 bit). The highest synchrony value was detected for the 'Buzău 47' variety (0.58) whereas the lowest value was detected for the 'Ștefănești 24' variety (0.09).

In the greenhouse (Figure 2), over 80\% emergence was observed for the 'Florina 44', 'Andrada', 'Buzau 47' and 'Ștefănești 22' varieties, whereas the 'Ștefănești 24 ' variety displayed the lowest percentage of emergence (34.4\%). The longest mean emergence time was observed for the 'Ștefănești 24 ' variety ( $\sim 17$ days). All the other varieties emerged between 8 and 10 days. In the case of homogeneity, expressed by the coefficient of variation of the emergence, there were no significant differences among the varieties studied at $\mathrm{P}<0.05$. Mean emergence rate varied significantly among the tomato varieties. In the case of uncertainty of emergence, the highest value was 


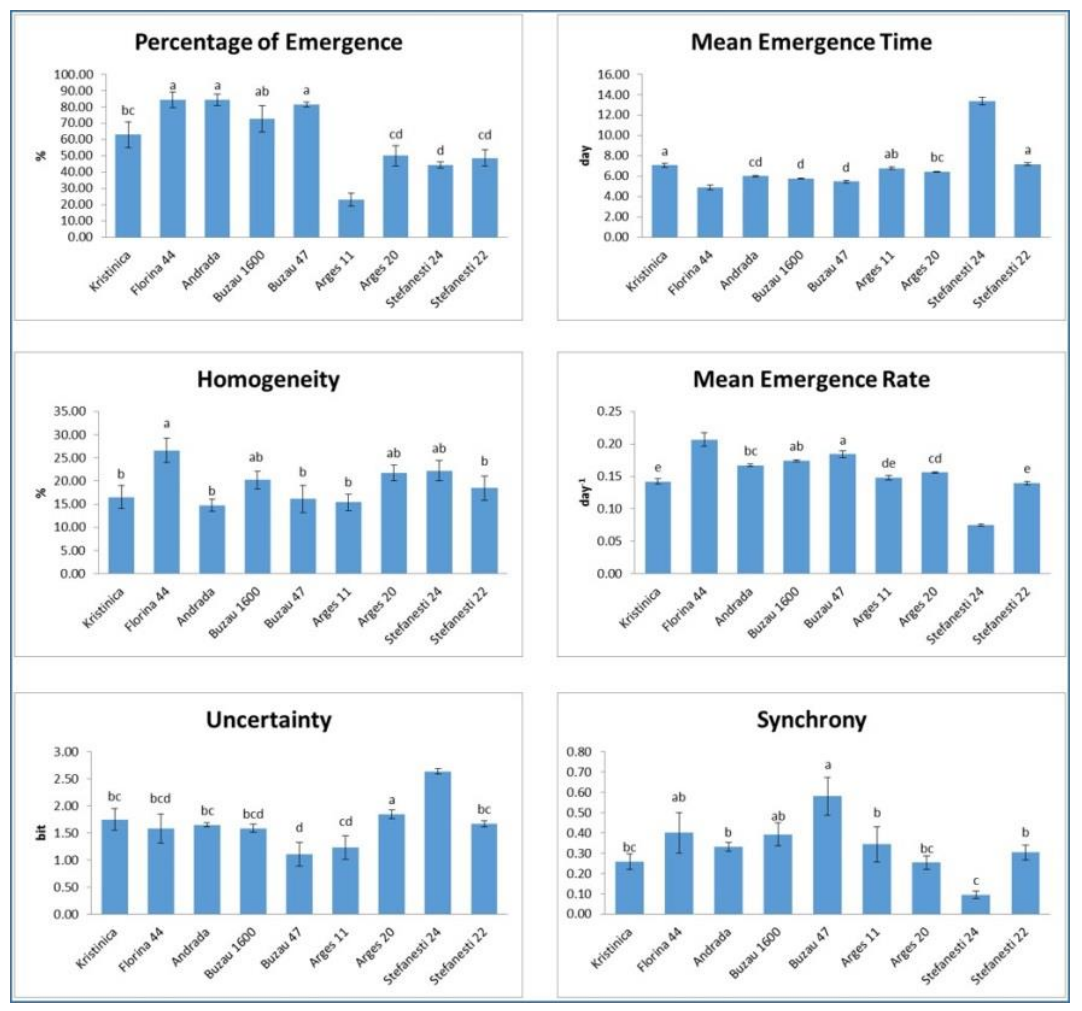

Figure 1. Seedling emergence indicators for the nine tomato varieties grown under growth chamber conditions. Error bars represent standard error of the mean. Bars with the same letters are not significantly different at $\mathrm{P}<0.05$ according to Duncan's multiple range test.

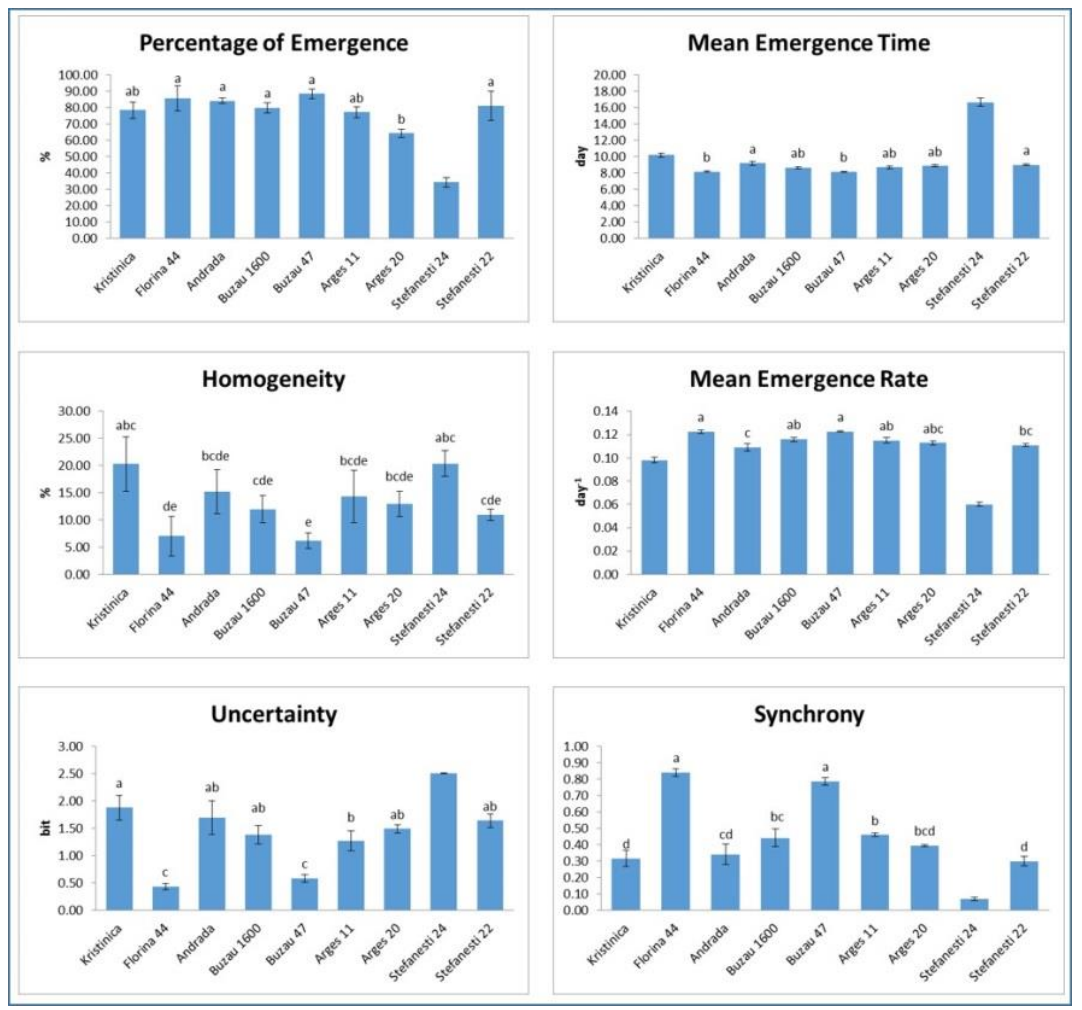

Figure 2. Seedling emergence indicators for the nine tomato varieties grown under greenhouse conditions. Error bars represent standard error of the mean. Bars with the same letters are not significantly different at $\mathrm{P}<0.05$ according to Duncan's multiple range test. 
observed for the 'Ștefănești 24 ' variety (2.51 bit) and the lowest value for the 'Florina 44 ' variety ( 0.23 bit). The highest synchrony value was detected for the 'Florina 44 ' variety $(0.84)$ whereas the lowest value was detected for the 'Ștefănești 24 ' variety (0.07). 'Ștefănești 24 ' displayed the longest mean emergence time and lowest mean emergence rate, lowest synchrony and highest uncertainty of emergence.

\section{Pepper seedling emergence}

Seven pepper varieties were compared for the same physiological indicators of seedling emergence. In the growth chamber (Figure 3), the highest percentage of emergence was observed for the varieties 'Galben Superior' (89.9\%), 'Splendens' (78.8\%) and 'Cosmin' (92,8\%), whereas the lowest percentage of emergence was observed for the 'Vladimir' variety $(10.00 \%)$. The shortest mean emergence time was noted for the 'Roial' variety ( $\sim 9$ days), and the longest emergence time was noted for 'Decebal' variety ( $\sim 22$ days). For the rest of the varieties, the mean emergence time values were between 12-17 days. The highest values for homogeneity were noted for 'Splendes' (36.6) and 'Cantemir' (36.9) varieties, whereas the lowest value was noted for the 'Vladimir' variety (6.5). The highest mean emergence rate was observed for the 'Roial' variety $\left(0.11\right.$ day $\left.^{-1}\right)$, and the lowest emergence rate was observed for the 'Decebal' variety $\left(0.08\right.$ day $\left.^{-1}\right)$. The highest value for the uncertainty was observed for 'Cosmin' variety ( $3.20 \mathrm{bit}$ ) and the lowest value for the 'Vladimir' variety ( $0.92 \mathrm{bit}$ ). The highest synchrony value was detected for the 'Vladimir' variety (0.33) whereas the lowest value was detected for the 'Deceba'l and 'Cosmin' varieties (0.08).

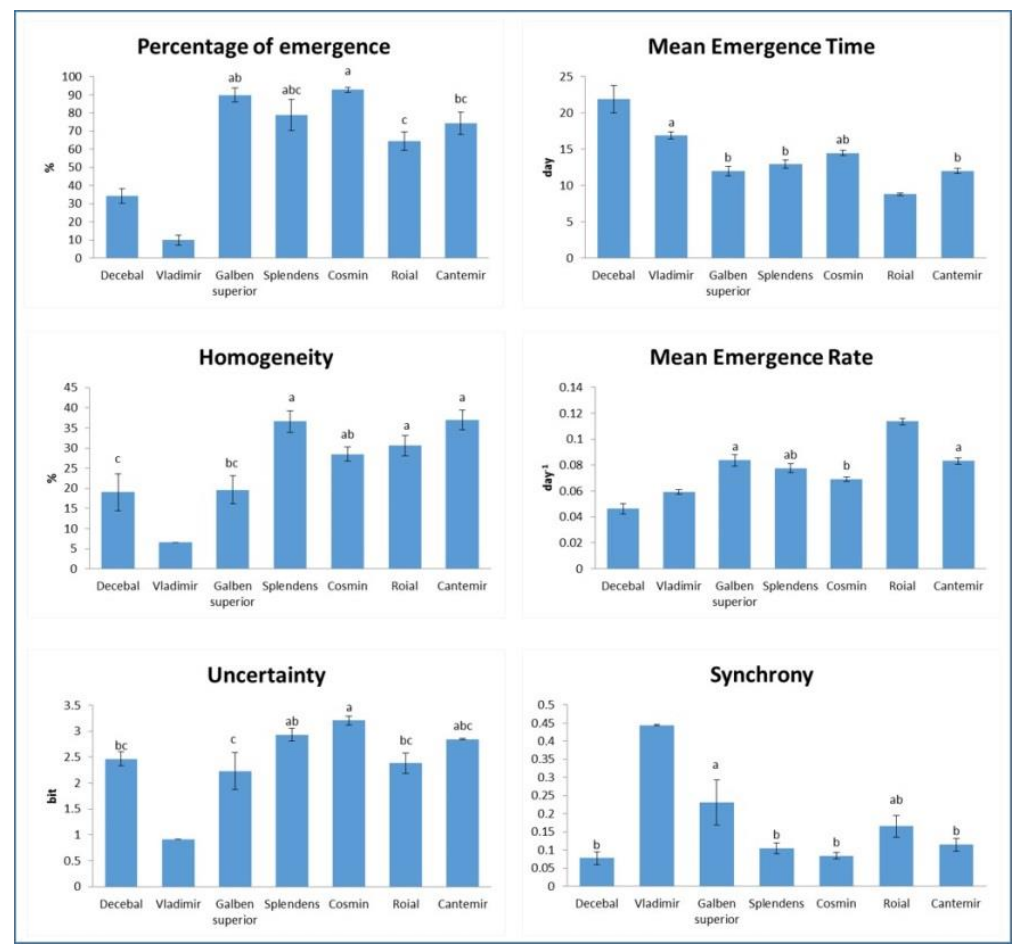

Figure 3. Seedling emergence indicators for the seven pepper varieties grown under growth chamber conditions. Error bars represent standard error of the mean. Bars with the same letters are not significantly different at $\mathrm{P}<0.05$ according to Duncan's multiple range test

In the greenhouse (Figure 4), four varieties displayed over 90\% percentage of emergence: 'Galben Superior' (97.2\%), 'Cosmin' (94.3\%), 'Roial' (91.5\%) and 'Cantemir' (92.9\%). The lowest percentage of emergence was observed for 'Vladimir' (12.9\%). The shortest mean emergence was noted for the 'Roial' variety ( 10 days), and the longest emergence time was noted for Vladimir variety ( $\sim 18$ days). For the rest of the varieties, the mean emergence time values were between 12-16 days. The highest homogeneity value was noted for 'Decebal' variety (15.9) whereas the lowest value was noted for 'Galben Superior' variety (7.6). The highest mean emergence rate was observed for 'Roial' variety $\left(0.10\right.$ day $\left.^{-1}\right)$, and the lowest emergence rate was observed for 'Vladimir' variety $(0.05$ day $^{-1}$ ). The highest uncertainty value was observed for 'Decebal' variety (2.66 bit) and the lowest value for 'Vladimir' variety (1.14 bit). The highest synchrony value was observed for 'Galben Superior' variety (0.29) whereas the lowest value was detected for 'Decebal' variety (0.11). Most published studies regarding seedling emergence involve various environmental conditions, seed treatments/pretreatments, and toxic substances that may influence this physiological process. 


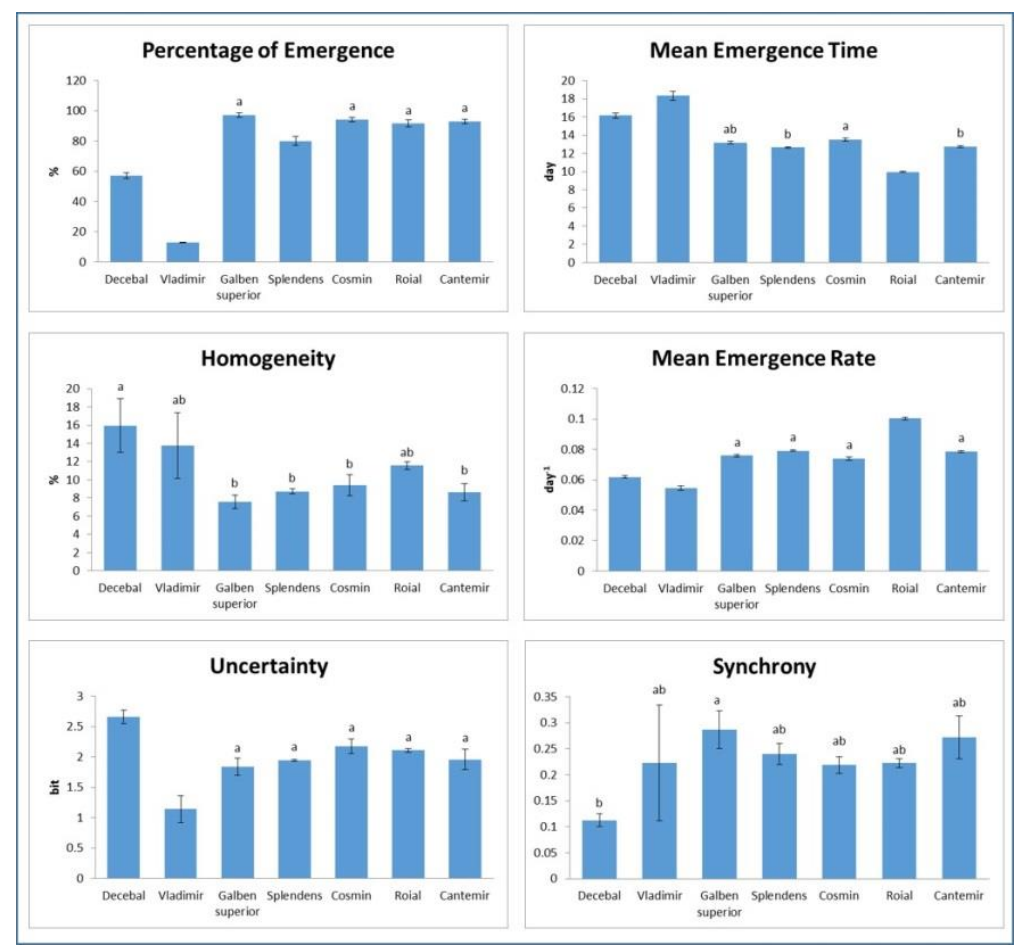

Figure 4. Seedling emergence indicators for the seven pepper varieties grown under greenhouse conditions. Error bars represent standard error of the mean. Bars with the same letters are not significantly different at $\mathrm{P}<0.05$ according to Duncan multiple range test.

Soil conditions may affect seedling emergence, either positively or negatively. For instance, rhizobacteria Pseudomonas fluorescens and Bacillus mycoides were shown to improve wheat seedling emergence and plant biomass (Czaban et al., 2004; Sivaramaiah et al., 2007). In addition, bacteria isolated from mud volcano and lime cave of Andaman and Nicobar Islands increased the percentage emergence for chili and tomato seedlings (Venkadesaperumal et al. 2014). Levy and Taylor (2003) published a study regarding the effects of several composts and pulp mill solids on tomato early growth. MSW (municipal solid waste) compost strongly inhibited tomato seedling emergence, whereas both race track compost and pulp mill solids showed improved emergence compared to pot soil only.

Pre-sowing seed treatments (priming) were reported to improve germination rate, emergence time, as well as synchrony in various crops (Parera and Cantliffe, 1994; Taylor et al., 1998; Farooq et al., 2009; Wang et al., 2016). Synchrony and fast emergence time is especially important when producing tomato rootstock seedlings, which are known to have slow and erratic emergence, reducing the efficiency of grafted seedling production. Mavi et al. (2006) reported the success of several treatments in reducing the mean emergence time and improving emergence synchrony of tomato rootstock seedlings. The seed priming treatment with $2 \% \mathrm{HNO}_{3}$ produced the best results in increasing the efficiency of grafted seedling production.

Among toxicity studies, DBDP-Ethane, a brominated flame retardant that accumulates in sewage sludge, proved to reduce significantly the emergence of cucumber seedlings (Hardy et al., 2011). In a recent study (Brain and Hoberg, 2016) performed in order to assess the effect of the herbicide atrazine on seedling emergence for several herbaceous species, including tomatoes, tomato seedlings emergence was affected negatively by the herbicide spray, however the plants were able to recover once the treatment ended.

Polyploidy can also affect seedling emergence. A study comparing diploid and tetraploid cytotypes of Centaurea stoebe, a herbaceous plant native in Europe, showed that the tetraploid type has an improved emergence compared to the diploid one, aiding it to become an invasive species in North America (Hahn et al., 2013).

An interesting experiment performed in the 1990s studied the effect of outer space on germination, emergence and fruit yield. Tomato seeds were exposed for 6 years to outer space (launched by the shuttle Challenger in 1984 and recovered by the crew of Columbia shuttle in 1990). No adverse effects on the emergence process were observed due to space exposure (Kahn and Stoffella, 1996). As opposed to the above mentioned studies, the present experience was performed with the purpose of comparing several varieties of the same species (tomato/pepper) during seedling emergence process. The results of this study will be correlated in future research with genotyping studies, with the ultimate goal of creating new, improved varieties in genotype-assisted breeding programs.

Romanian customers prefer to consume local tomato and pepper varieties, so breeding programs are delivering new varieties using local landraces that are well adapted to the local ecological conditions. 'Ștefănești 24 ' tomato 
variety appears to have the lowest percentage of emergence, the lowest synchrony value, and longest time to emerge. However, this variety has been shown to have a high production, $9.8 \mathrm{~kg} /$ plant and 290 t/ha (Bădulescu and Uleanu, 2017). 'Kristinica' tomato variety, besides a good percentage of seedling emergence, has been shown to be resistant/tolerant to several pathogens such as Fusarium oxysporum sp. lycopersici, Phytophthora infestans, Verticillium dahliae (Mîndru et al., 2019). This variety is also an early one, as its fruits are reaching the physiological maturity at 90 days after planting and it is preferred for industry, since the fruits have over 30 days shelf life (Vînătoru et al., 2016). One of the varieties of pepper from the present study, 'Decebal', was patended in 2015 from the 'Cornul Caprei' landrace, which has been cultivated in Buzău region for more than 200 years and shows an improved yield compared to the original landrace (Tudor et al. 2019) in spite of low percentage of emergence and low synchrony values.

Tomato germplasm colection at V.R.D.S. Buzău has over 1500 genotypes (Zamfir et al., 2017) and pepper germplasm collection over 200 lines (Lagunovschi-Luchian et al., 2016). In the future, further genotyping studies are needed to correlate the phenotyping traits studied in this survey with DNA sequence differences, in order to select plants with multiple superior traits in genotype-assisted breeding programs, and select against undesirable traits, with the final goal of creating novel valuable ecological varieties of tomato and pepper, which will appeal to the Romanian consumers.

\section{CONCLUSIONS}

Significant differences in the seedling emergence indicators were observed among the tomato and pepper varieties studied, both in growth chamber and in greenhouse.

Among the tomato varieties, 'Ștefănești 24' displayed the longest mean emergence time and lowest mean emergence rate, and the lowest synchrony and highest uncertainty of emergence values.

Among the pepper varieties studied, 'Vladimir' showed the lowest values for percentage of emergence $(10.0 \%$ growth chamber $12.9 \%$ greenhouse), homogeneity $(6.5 \% / 13.7 \%)$ and uncertainty of emergence ( 0.9 bit $/ 1.1$ bit).

Author Contributions: M.I. and A.A.U. conceived and designed the experiment. M.I. collected the data, performed data analysis, and wrote the paper. A.A.U. and L.B supervised the project. J.O. contributed data and analysis tools.

Funding Source: This research work was founded by the Romanian Ministry of Agriculture and Rural Development (MADR), under the Agricultural Research and Development Program 2019-2022, ADER 7.2.6 project.

\section{Conflicts of Interest}

The authors declare that they do not have any conflict of interest.

\section{REFERENCES}

1. Barcanu-Tudor E, Drăghici EM, Vînătoru C (2018). New Variety of Sweet Pepper (Capsicum annuum var. Grossum) Obtained at VRDS Buzău. Bulletin of UASVM Cluj-Napoca. Horticulture, 75(1): 1-3.

2. Bădulescu A, Uleanu F (2017). New valuable genotypes of tomato added in culture to INCDBH Stefanesti-Arges. Current Trends in Natural Sciences, 6(12): 83-87.

3. Brain RA, Hoberg J (2016). Recovery of terrestrial plants in vegetative vigor and seedling emergence tests from exposure to atrazine. Environmental Toxicology and Chemistry, 35(5): 1284-1296.

4. Briggs WR (2016). Plant biology: seedling emergence through soil. Current Biology, 26(2): R68-R70.

5. Bujor OC, Dobrin A, Stan A, Mot A, Badulescu L (2019). Changes in carotenoid content of organic tomato powders depending in drying parameters. Proceedings of Eurodrying 10-12 July 2019, Torino, Italy, 413-414.

6. Coe S, Spiro A, Lockyer S, Stanner S (2019). Ensuring a healthy approach to long-term weight management: Review of the Slimming World programme. Nutrition Bulletin, 44(3): 267-282.

7. Czaban J, Ksiezniak A, Perzynski A (2004). An attempt to protect winter wheat against Fusarium culmorum by the use of rhizobacteria Pseudomonas fluorescens and Bacillus mycoides. Polish journal of microbiology, 53(3): 175-182.

8. Delian E, Bădulescu L, Dobrescu A (2012). Plant physiology. Practical works. II ed. Edit. Universitară Bucuresti, pp. 145.

9. Dobrin A, Nedeluș A, Bujor O, Moț A, Zugravu M, Bădulescu L (2019). Nutritional quality parameters of the fresh red tomato varieties cultivated in organic system. Scientific Papers-Series B, Horticulture (1): 439-444.

10. Farooq M, Basra SMA, Wahid A, Khaliq A, Kobayashi N. (2009). Rice seed invigoration: a review. Organic farming, pest control and remediation of soil pollutants, 137-175. 
11. Foolad MR, Panthee DR (2012). Marker-assisted selection in tomato breeding. Critical reviews in plant sciences, 31(2): 93-123.

12. Forcella F, Arnold RLB, Sanchez R, Ghersa CM (2000). Modeling seedling emergence. Field Crops Research, 67(2): 123-139.

13. Hahn MA, Lanz T, Fasel D, Müller-Schärer H (2013). Increased seed survival and seedling emergence in a polyploid plant invader. American journal of botany, 100(8): 1555-1561.

14. Hardy ML, Aufderheide J, Krueger HO, Mathews ME, Porch JR, Schaefer EC, Stedeford T (2011). Terrestrial toxicity evaluation of decabromodiphenyl ethane on organisms from three trophic levels. Ecotoxicology and environmental safety, 74(4): 703-710.

15. Kahn BA, Stoffella PJ (1996). No evidence of adverse effects on germination, emergence, and fruit yield due to space exposure of tomato seeds. J. of the American Society for Hort. Science, 121(3): 414-418.

16. Khan N, Kazmi RH, Willems LA, Van Heusden AW, Ligterink W, Hilhorst HW (2012). Exploring the natural variation for seedling traits and their link with seed dimensions in tomato. PLoS One, 7(8), e43991.

17. Kim C, Guo H, Kong W, Chandnani R, Shuang LS, Paterson AH (2016). Application of genotyping by sequencing technology to a variety of crop breeding programs. Plant Science, 242: 14-22.

18. Lagunovschi-Luchian V, Vinatoru C, Zamfir B, Bratu C (2016). New genotypes of hot peppers with distinct phenotypic expressivity. Romanian Biotechnological Letters, 21(3): 11451.

19. Levy JS, Taylor BR (2003). Effects of pulp mill solids and three composts on early growth of tomatoes. Bioresource Technology, 89(3): 297-305.

20. Mavi K, Ermis S, Demir I (2006). The effect of priming on tomato rootstock seeds in relation to seedling growth. Asian Journal of Plant Sciences, 5(6): 940-947.

21. Maxim V, Linnemannstön L, Maniutiu D, Maxim A, Sandor M, Creţa C, Gocan T (2013). Suitability of Some Romanian Tomato Landraces to Organic Crop in Plastic Tunnel. Bulletin of UASVM Cluj-Napoca. Horticulture, 70(1): 164-171.

22. Mîndru I, Costache M, Sovarel G, Cenusa AE, Hoza D, Cristea S (2019). Researches concerning the behavior of some cultivars of tomatoes (Lycopersicon esculentum Mill.) in Vidra area, Ilfov county. Scientific Papers. Series B, Horticulture, Vol. LXIII (2): 149-154.

23. Parera CA, Cantliffe DJ (1994). Presowing seed priming. Horticultural reviews, 16(16): 109-141.

24. Ranal MA, Santana DGD (2006). How and why to measure the germination process? Brazilian Journal of Botany, 29(1): 1-11.

25. Ranal MA, Santana DGD, Ferreira WR, Mendes-Rodrigues C (2009). Calculating germination measurements and organizing spreadsheets. Brazilian Journal of Botany, 32(4): 849-855.

26. Rocha MDC, Deliza R, Corrêa FM, do Carmo MG, Abboud AC (2013). A study to guide breeding of new cultivars of organic cherry tomato following a consumer-driven approach. Food Research International, 51(1): $265-273$.

27. Santos HO, Von Pinho EVR, Von Pinho IV, Dutra SMF, Andrade T, Guimarães RM (2015). Physiological quality and gene expression during the development of habanero pepper (Capsicum chinense Jacquin) seeds. Genetics and Molecular Research, 14(2): 5085-5098.

28. Sivaramaiah N, Malik DK, Sindhu SS (2007). Improvement in symbiotic efficiency of chickpea (Cicer arietinum) by coinoculation of Bacillus strains with Mesorhizobium sp. Cicer. Indian journal of microbiology, 47(1): 51-56.

29. Taylor AG, Allen PS, Bennett MA, Bradford KJ, Burris JS, Misra MK (1998). Seed enhancements. Seed science research, 8(2): 245-256.

30. Tobler C, Visschers VH, Siegrist M (2011). Eating green. Consumers' willingness to adopt ecological food consumption behaviors. Appetite, 57(3): 674-682.

31. Tudor EB, Vînătoru C, Mușat B, Bratu C, Dobre OL, Drăghici EM (2019). Expressiness of the main characteristics in 'Decebal', a long pepper variety. Sci. Papers-Series B, Horticulture, 63(1): 407-410.

32. Venkadesaperumal G, Amaresan N, Kumar K (2014). Plant growth promoting capability and genetic diversity of bacteria isolated from mud volcano and lime cave of Andaman and Nicobar Islands. Brazilian Journal of Microbiology, 45(4): 1271-1281.

33. Vînătoru C, Neicu E (2010). New and perspective tomato lines with determined growing obtained at VRDS Buzău. Bulletin of UASVM Cluj-Napoca. Horticulture, 67(1).

34. Vînătoru C, Zamfir B, Bratu C, Lăcătuș V, Cârstea L (2016). New processing tomato varieties obtained at VRDS Buzău. Scientific Papers-Series B, Horticulture, (60): 155-160.

35. Wang W, Chen Q, Hussain S, Mei J, Dong H, Peng S, Nie L (2016). Pre-sowing seed treatments in direct-seeded early rice: consequences for emergence, seedling growth and associated metabolic events under chilling stress. Scientific reports, 6(1): 1-10.

36. Weaver SE, Tan CS, Brain P (1988). Effect of temperature and soil moisture on time of emergence of tomatoes and four weed species. Canadian Journal of Plant Science, 68(3): 877-886.

37. Zamfir B, Hoza D, Vînătoru C, Lagunovschi V, Bratu C, Bărcanu E (2017). Research on conservation, evaluation and genetic heritage exploitation of tomato. Scientific Papers-Series B, Horticulture, (61): 307-312. 